\title{
KONSEP DIRI AKADEMIK MAHASISWA PASCASARJANA
}

\author{
Zuvyati A. Tlonaen, Jusuf Blegur \\ aryanietlonaen@gmail.com, blegur04@yahoo.co.id \\ Magister Pendidikan Bahasa dan Sastra Inggris, Unesa \\ Fakultas Keguruan dan Ilmu Pendidikan, UKAW \\ POSTGRADUATE STUDENTS' ACADEMIC SELF-CONCEPT
}

\begin{abstract}
This research reports the assessment of academic self-concept of the first semester postgraduate students of education, in language and literature program, Surabaya State University. This research used descriptive quantative method. Respondents involved were 20 students $(M=25.2500, S D=$ $2.46822)$ in which the determination of the respondents were done by the use of the total sampling. The data were collected using the Academic Self-Concept Questionnaire (ASCQ) developed by Woon C. Liu and Chee K. J. Wang in 2005 by involving two dimensions, that is of academic-conviction and academic effort. The result of the analysis indicated that 13 students $(65 \%)$ responded to the research questionnaire in the value of 80-100, and 7 students (35\%) responded to the questionnaire in the value of 60-80, whereas in the value of 40-60, and of 0-20 were not responded by the students (0\%). Finally, it can be inferred that students' academic self-concept are very good (65\%).
\end{abstract}

Keywords: Academic self-concept, postgraduate students.

\section{Article Info}

\section{PENDAHULUAN}

Konsep diri sebagai komponen pengembangan kepribadian manusia yang memiliki sifat dan kekhasan sendiri (Ghazvini, 2011:1035), mencerminkan pandangan umum individu atas penerimaan dan kompetensi sosial, yaitu perasaan pribadi tentang dirinya sendiri (Bellmore \& Cillessen, 2006:210). Dalam urusan akademik, konsep diri merupakan komposit umum individu atau pandangan kolektif diri sendiri terhadap persepsi multidimensi akademik berdasarkan kemampuan diri dan evaluasi nilai yang dibentuk melalui pengalaman dan interpretasi atas lingkungan sosial (Sternke, 2010:15).

Pandangan Sternke di atas menjelaskan lingkungan berperan dalam pengembangan kepribadian individu. Kontribusinya tidak terbatas pada sejumlah domain afektif yang menetap dalam lingkungan sejak lahir, namun juga mempengaruhi preferensi sosial, perkembangan konsep diri akademik, dan prestasi akademik individu (Baran \& Maskan, 2011:2; Srivastava \& Joshi, 2011:331; Bellmore \& Cillessen, 2006:209). Hal ini secara luas menyiratkan konsep diri akademik berkembang sebagai implikasi atas interaksi mahasiswa dalam lingkungan sekitarnya, bisa dengan orang tua, rekanrekan, maupun dosen.

Kerberhasilan mahasiswa dalam mengikuti proses pendidikan dan pembelajaran di kampus sangat dipengaruhi oleh konsep diri akademiknya (Flowers, Raynor, \& White, 2013:1; Tan \& Yates, 2007:471). Mahasiswa terkondisi untuk mempersepsikan dirinya sebagai pembelajar serta bagaimana dirinya berinteraksi dengan lingkungan belajarnya (Emmanuel, Adom, Josephine, \& Solomon, 2014:27) yang termanifestasi melalui keyakinan akademik dan usaha akademiknya (Liu \& Wang, 2005:21) dalam proses belajar di kelas maupun di luar kelas, misalnya dengan menyajikan presentasi maupun menuliskan uraian.

Konsep diri akademik yang positif mendatangkan keyakinan mahasiswa atas segenap potensi atau kemampuanya dalam bidang akademik. Ia pula merasa dirinya lebih unggul dari mahasiswa lainnya dalam kegiatan akademik (Ellingsen, 2013:viii; Baran \& Maskan, 2011:2). Serta diiringi 
dengan usaha-usaha akademik untuk mewujudnyatakan persepsi akademik tersebut. Oleh sebabnya, konsep diri akademik memainkan posisi penting selama berlangsungnya kegiatan pembelajaran. Spesifikasinya dengan melatih fungsi kognitif mahasiswa untuk memberikan performa dan prestasi akademik yang lebih apik (Ordaz-Villegas, Acle-Tomasini, \& Reyes-Lagunes, 2013:117).

Saat berlangsungnya pembelajaran, mahasiswa sibuk dengan gadget-nya, perhatian belajarnya melemah, dan tidak fokus mengikuti kegiatan pembelajaran. Situasi lain yaitu adanya perasaan skeptis terhadap kemampuan akademiknya. Mendapat banyak interupsi dari pendidik, saat memaparkan materi presentasi sehingga mahasiswa ingin meninggalkan kelas secara cepat. Selain itu, mahasiswa enggan menunjukkan usaha akademik, serta mudah menyerah saat menghadapi tugas yang "menantang". Inilah bentuk buruknya konsep diri akademik mahasiswa (Liu \& Wang, 2005:22) yang dapat mempengaruhi perilaku "agresi" dalam proses pembelajaran (Taylor, Davis-Kean, \& Malanchuk, 2007:131).

Permasalahan keyakinan dan usaha akademik di atas adalah penghambat aktualiasi diri mahasiswa. Padahal, model peningkatan diri menjelaskan konsep diri akademik merupakan penentu prestasi akademik. Ini berarti performa dan prestasi akademik sebagai konsekuensi positif dari konsep diri akademik, begitu pun sebaliknya (Emmanuel, Adom, Josephine, \& Solomon, 2014:24; Chen, Yeh, Hwang, \& Lin, 2013:172; Dramanu \& Balarabe, 2013:95; Ghazvini, 2011:1034). Arah kausalitasnya berawal dari intervensi konsep diri akademik yang dilegitimasi kayakinan diri dalam mengabdikan usaha dan komitmen guna meningkatkan status akademik (peningkatan diri) (Green, Nelson, Martin, \& Marsh, 2006:536; Liu \& Wang, 2005:22).

Konsep diri akademik ada pada setiap mahasiswa yang terlibat dalam proses pembelajaran, dan idealnya konsep diri akademik linear dengan tingkat pendidikan individu. Kian tinggi level pendidikan, soyogianya kian baik pula himpunan pengetahuan dan sikap yang dimiliki mahasiswa atas status akademiknya. Atas rasionalisasi demikian, maka penelitian ini dilaksanakan untuk menilai konsep diri akademik mahasiswa semester I program studi S2 pendidikan bahasa dan sastra Inggris program pascasarjana Universitas Negeri Surabaya. Penelitian ini juga bermanfaat untuk mengklasifikasi dan membandingkan konsep diri akademik sesuai dengan tingkat pendidikan tertentu. Serta sebagai media untuk memperbaiki konsep diri akademik mahasiswa pascasarjana.

\section{METODE PENELITIAN}

Pendekatan yang digunakan dalam penelitian ini adalah kuantitatif dengan jenis deskriptif. Populasi yang dipakai adalah mahasiswa semester I program studi S2 pendidikan bahasa dan sastra Inggris (kelas reguler) Program Pascasarjana, Universitas Negeri Surabaya. Sampel yang terlibat dalam penelitian ini berjumlah 20 orang, terdiri dari 8 orang laki-laki dan 12 orang perempuan $(M=$ $25.2500, \mathrm{SD}=2.46822$ ) yang penetapannya menggunakan teknik total sampling.

Data penelitian dikumpulkan menggunakan Academic Self-Concept Questionnaire (ASCQ) yang dikembangkan oleh Woon C. Liu dan Chee K. J. Wang di tahun 2005 yang kemudian dimodifikasi sejumlah redaksi agar sesuai dengan konteks pendidikan pascasarjana $(r=.73)$. ASCQ melibatkan 20 pernyataan tertutup yang terdiri dari 2 sub variabel, antara lain: 1) Keyakinan akademik, yaitu penilaian tentang perasaan dan persepsi mahasiswa tentang kompetensi akademik yang diimilikinya. Sub variabel ini terwakili 10 pernyataan bernomor ganjil. 2) Usaha akademik, penilaian tentang komitmen mahasiswa tentang keterlibatannya pada proses pembelajaran. Sub variabel ini terwakili 10 pernyataan bernomor genap.

Proses analisis menggunakan deskriptif kuantitatif dengan bantuan SPSS 20 for windows. Hasil analisis data (ferkuensi dan persentasi) kemudian diinterpretasikan sebagai berikut: sangat baik (80-100), baik (60-80), cukup baik (40-60), kurang baik (20-40), dan tidak baik (0-20).

\section{HASIL DAN PEMBAHASAN Keyakinan Akademik}

Pada dimensi keyakinan akademik, responden dinilai perasaan dan persepsinya tentang kompetensi akademik yang dimilikinya. Dari 10 pernyataan yang ditanggapi responden, seluruhnya memberikan jaminan kepada derajat keyakinan akademik yang baik $(\mathrm{M}=38 ; \mathrm{SD}=4.14221)$. 
Tabel 1. Frekuensi dan Persentase Keyakinan Akademik Responden

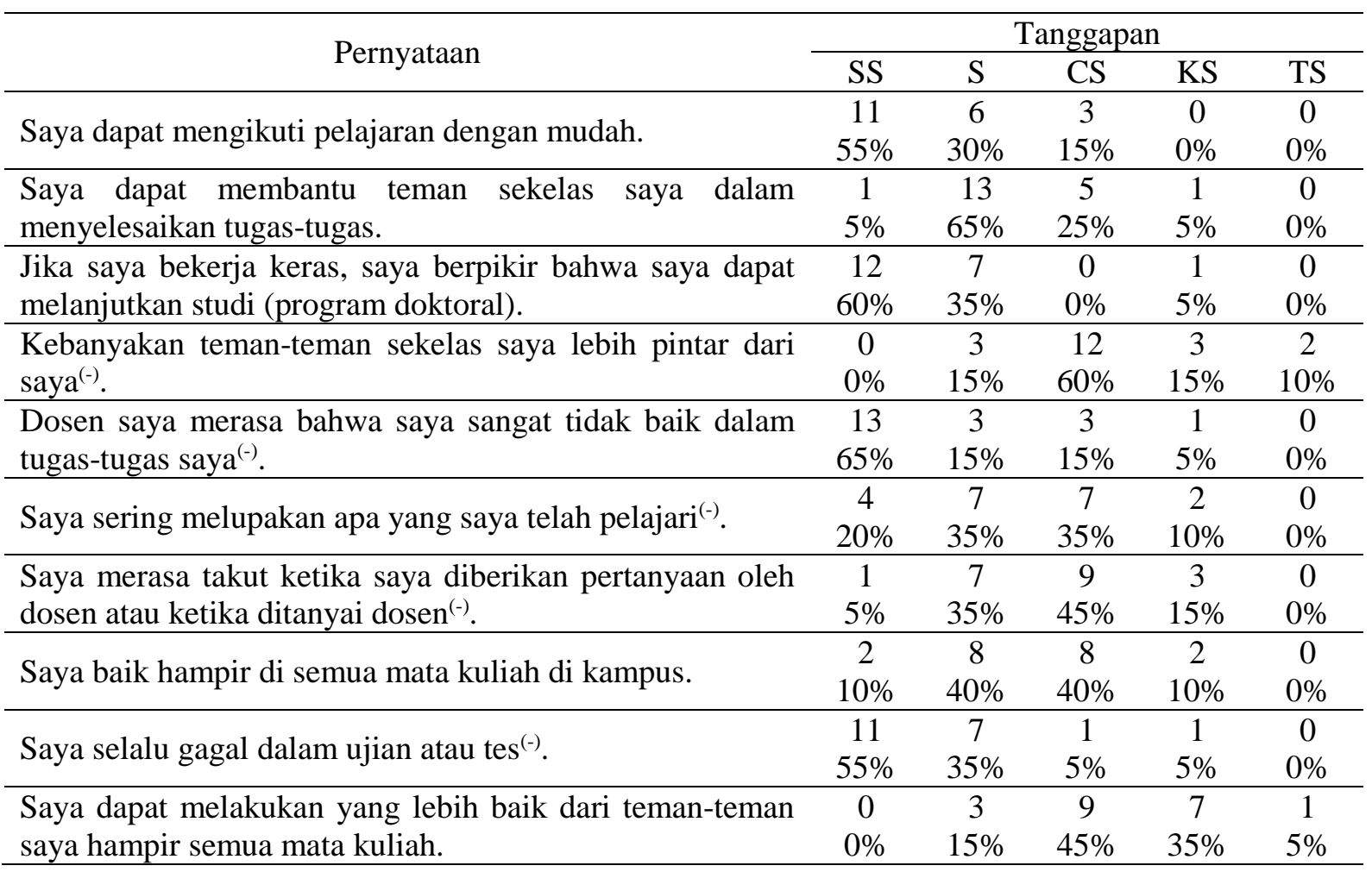

Catatan: SS (sangat sesuai), S (sesuai), CS (cukup sesuai), KS (kurang sesuai), TS (tidak sesuai).

Mahasiswa lazimnya yakin terhadap kemampuan akademik yang milikinya hingga memudahkannya saat mengikuti proses pembelajaran (Flowers, Raynor, \& White, 2013:1; Tan \& Yates, 2007:471) serta memiliki performa akademik yang baik (Ghazvini, 2011:1037). Pembelajaran tidak dilihat sebagai sesuatu yang sulit atau memberatkan, justru sebaliknya. Unggul secara akademik, membuat mereka saling menunjukkan sikap kooperatif diantara sesama teman saat menyelesaikan tugas-tugas akademik.

Hal ini sangatlah nampak, sebab proses pembelajaran didesain dalam dua metode belajar utama, yakni metode presentasi dan metode tugas uraian. Kedua metode kian memudahkan mahasiswa untuk menyalurkan dan mewujudkan keyakinan akademiknya. Sebagai contoh, pada saat menyampaikan materi sudah mesti modal dasar yang dimiliki adalah keyakinan terhadap diri sendiri dan disitulah awal dari ketuntasan atau keberhasilannya. Mahasiswa berani menampilkan dirinya serta tenang dan santai saat "berorasi" di depan kelas.

Selain tugas presentasi, tugas uraian juga selalu mendapat umpan balik positif dari dosen. Lembar kerja mereka dihiasi dengan kata "good work". Hal ini pun kian melegitimasi mahasiswa atas kemampuan akademiknya. Malahan apresiasi dan keberhasilan tersebut menjadi strategi baru dalam menyelesaikan tugas uraian lainnya yang diberikan oleh dosen. Ini merupakan representasi kognitif mahasiswa atas dirinya sendiri saat menyelesaikan tugas belajar dari dosen selama terjadinya proses pembelajaran semesteran (Taylor, Davis-Kean, \& Malanchuk, 2007:131).

Meski umumnya mahasiswa menunjukkan persepsi dan perilaku keyakinan akademik yang baik, tetap saja persiapan sangat diperlukan untuk mengafirmasi keyakinan tersebut. Mahasiswa yang minim persiapan cenderung mengelak pertanyaan-pertanyaan yang diutarakan dosen, bahkan sering keluar masuk kelas saat pembelajaran berlangsung. Inilah catatan-catatan pengembangan konsep diri yang negatif di kalangan mahasiswa (Ghazvini, 2011:1035; Liu \& Wang, 2005:22).

Mapannya keyakinan akademik bukan secara spontanitas, melainkan adanya persepsi afirmatif yang memicunya serta komitmen melatih dan menekuninya. Bisa saja dari rekam jejaknya mahasiswa pada pengalaman belajar sebelumnya (diapreasi, IPK yang tinggi, publikasi ilmiah, dll.), tingkat usia 
(remaja dan dewasa) (Chen, Yeh, Hwang, \& Lin, 2013:172; Ghazvini, 2011:1038), status sosial (menikah dan lajang), dan gaya mengajar dosen. Semuanya berpengaruh terhadap tingkat persiapan mahasiswa untuk mengikuti proses pembelajaran dan menuntaskan tugas.

Selama sikap, perasaan, persepsi keyakinan akademik mahasiswa baik, maka dirinya akan yakin dan percaya terhadap kemampuan akademik yang dimilikinya (Dramanu \& Balarabe, 2013:94). Ini tidak berdiri secara parsial dari atribut lainnya. Keyakinan ini lahir karena adanya berbagai pengalaman yang dilewati mahasiswa dalam interaksi dan interpretasi lingkungan sosialnya (Sternke, 2010:15). Apalagi belajar dalam lingkungan yang "baru", masa pengamatan sangat membantu mahasiswa melakukan evaluasi terhadap keyakinan akademik dirinya sendiri dengan mediasi aktivitas akademik rekan-rekan kelas.

\section{Usaha Akademik}

Pada dimensi usaha akademik, responden diukur dalam komitmennya untuk berpartisipasi penuh pada proses pembelajaran. Dari 10 pernyataan yang ditanggapi responden, seluruhnya memberikan jaminan kepada derajat usaha akademik yang sangat baik $(M=43.75 ; S D=4.70022)$.

Saat mahasiswa mempersepsikan kemampuan atau kompetensinya dibidang akademik, maka dimensi usaha akademik akan mengarahkan dan menunjukkan usaha-usaha apa saja yang dilakukan mahasiswa sebagai seorang pembelajar dalam menyikapi lingkungan belajar guna mencapai performa dan prestasi akademik (Emmanuel, Adom, Josephine, \& Solomon, 2014:27; Dramanu \& Balarabe, 2013:95; Ghazvini, 2011:1034). Usaha ini dilakukan secara komprehensif dan sustanaibel disetiap interaksi dalam lingkungan belajarnya (kampus atau kos).

Tabel 2. Frekuensi dan Persentase Usaha Akademik Responden

\begin{tabular}{|c|c|c|c|c|c|}
\hline \multirow{2}{*}{ Pernyataan } & \multicolumn{5}{|c|}{ Tanggapan } \\
\hline & SS & $S$ & CS & KS & TS \\
\hline \multirow{2}{*}{ Saya banyak menghayal di dalam kelas ${ }^{(-)}$. } & 11 & 3 & 3 & 3 & 0 \\
\hline & $55 \%$ & $15 \%$ & $15 \%$ & $15 \%$ & $0 \%$ \\
\hline \multirow{2}{*}{ Saya sering mengerjakan tugas tanpa berpikir ${ }^{(-)}$. } & 11 & 6 & 0 & 3 & 0 \\
\hline & $55 \%$ & $30 \%$ & $0 \%$ & $15 \%$ & $0 \%$ \\
\hline \multirow{2}{*}{$\begin{array}{l}\text { Saya memperhatikan dosen selama berlangsungnya } \\
\text { perkuliahan. }\end{array}$} & 8 & 12 & 0 & 0 & 0 \\
\hline & $40 \%$ & $60 \%$ & $0 \%$ & $0 \%$ & $0 \%$ \\
\hline \multirow{2}{*}{ Saya belajar dengan giat untuk ujian atau mengikuti tes. } & 11 & 9 & 0 & 0 & 0 \\
\hline & $55 \%$ & $45 \%$ & $0 \%$ & $0 \%$ & $0 \%$ \\
\hline \multirow{2}{*}{ Saya selalu tertarik mengerjakan tugas-tugas saya. } & 10 & 4 & 5 & 1 & 0 \\
\hline & $50 \%$ & $20 \%$ & $25 \%$ & $5 \%$ & $0 \%$ \\
\hline \multirow{2}{*}{$\begin{array}{l}\text { Saya berkeinginan melakukan yang terbaik untuk lulus } \\
\text { semua mata kuliah. }\end{array}$} & 15 & 5 & 0 & 0 & 0 \\
\hline & $75 \%$ & $25 \%$ & $0 \%$ & $0 \%$ & $0 \%$ \\
\hline \multirow{2}{*}{$\begin{array}{l}\text { Saya sering merasa ingin keluar dari kampus atau tidak } \\
\text { ingin } \text { kuliah }^{(-)} \text {. }\end{array}$} & 18 & 2 & 0 & 0 & 0 \\
\hline & $90 \%$ & $10 \%$ & $0 \%$ & $0 \%$ & $0 \%$ \\
\hline \multirow{2}{*}{ Saya selalu menunggu kapan pembelajaran berakhir ${ }^{(-)}$. } & 1 & 7 & 7 & 5 & 0 \\
\hline & $5 \%$ & $35 \%$ & $35 \%$ & $25 \%$ & $0 \%$ \\
\hline \multirow{2}{*}{$\begin{array}{l}\text { Saya tidak mudah menyerah ketika menghadapi } \\
\text { kesulitan dalam tugas-tugas. }\end{array}$} & 11 & 6 & 2 & 0 & 1 \\
\hline & $55 \%$ & $30 \%$ & $10 \%$ & $0 \%$ & $5 \%$ \\
\hline \multirow{2}{*}{$\begin{array}{l}\text { Saya tidak ingin terlalu berusaha dalam mengerjakan } \\
\text { tugas-tugas saya }{ }^{(-)} \text {. }\end{array}$} & 13 & 5 & 1 & 1 & 0 \\
\hline & $65 \%$ & $25 \%$ & $5 \%$ & $5 \%$ & $0 \%$ \\
\hline
\end{tabular}

Catatan: SS (sangat sesuai), S (sesuai), CS (cukup sesuai), KS (kurang sesuai), TS (tidak sesuai).

Secara populatif, jumlah mahasiswa tergolong "kecil" sehingga kegiatan pembelajaran lebih menekankan pada pengembangan keterampilan individu (berpikir, menulis, dan menyampaikan). Mahasiswa melaksanakan presentasi dan menyelesaikan uraian lebih dari satu kali untuk setiap mata kuliah. Sebut saja untuk mata kuliah "General outlook of literature", setiap mahasiswa melaksanakan 5 kali presentasi. Sedangkan mata kuliah "Pragmatics, linguistic, dan English an international language" setiap mahasiswa menyelesaikan 5 uraian selama proses pembelajaran ( 1 semester). 
Meski tidak sama secara kuantitas, ini berlaku untuk mata kuliah lainnya sehingga usaha sangatlah penting. Waktu lebih banyak mahasiswa fokus dan investasikan dalam kegiatan pembelajaran (Jen \& Chien, 2008:1). Tugas-tugas dikerjakan dengan apik, perilaku belajar yang giat selalu ditunjukkan untuk setiap aktivitas belajar, tidak hanya saat memasuki tes atau ujian, namun selama proses pembelajaran terjadi. Membaca dan menganalisis narasi dalam buku teks maupun jurnal dikediaman (rumah dan kos) lalu dikontekstualisasikan dalam kehidupan nyata adalah salah satu usaha yang dilakukan mahasiswa agar dapat mendiskusikan hasil analisis yang bermakna dengan rekan lainnya.

Tidak ada usaha positif yang membuahkan hasil negatif. Jikapun ada usaha yang belum berhasil maka itu hanyalah penundaan yang memerlukan alternatif solusinya, bukan menghentikan usahanya. Mahasiswa harus distimulasi untuk melakukan usaha-usaha akademik yang dapat dipertanggungjawab secara akademik pula sebagai strategi melatih fungsi kognitifnya (OrdazVillegas, Acle-Tomasini, \& Reyes-Lagunes, 2013:117). Evaluasi secara langsung sebagai salah satu langkah efektif yang digunakan dosen untuk menilai produk usaha setiap mahasiswanya (Sternke, 2010:15). Evaluasi diri juga memberikan masukan kritis kepada mahasiswa agar selalu dan senantiasa memperbaiki usaha dan performa akademiknya dalam kelas (Goldberg, 2014:2-3).

Semua mahasiswa ingin maksimal atas performa dan prestasi akademiknya. Inilah kesadaran moril atas tuntutan akademiknya saat kelak menyandang status sebagai seorang masgister pendidikan (apapun profesinya). Selain itu, usaha-usaha ini bertujuan untuk membiasakan mahasiswa agar selalu berusaha dan bekerja keras dalam menjawab tuntutan lingkungan kerja ketika menjalankan tugas dan tanggung jawabnya. Sebagai dosen yang berkualitas dan kompeten adalah salah satu contoh pengembangan dari dimensi usaha akademik.

\section{Konsep Diri Akademik}

Rangkuman hasil analisis data menemukan konsep diri akademik responden tergolong sangat baik (lihat gambar 1). Simpulan ditarik berdasarkan hasil analisis data yang menjelaskan bahwa 13 responden $(65 \%)$ responden menanggapi kuesioner penelitian yang mengarah pada rentang nilai 80100 (sangat baik) dan 7 responden (35\%) pada rentang nilai 60-80 (baik).

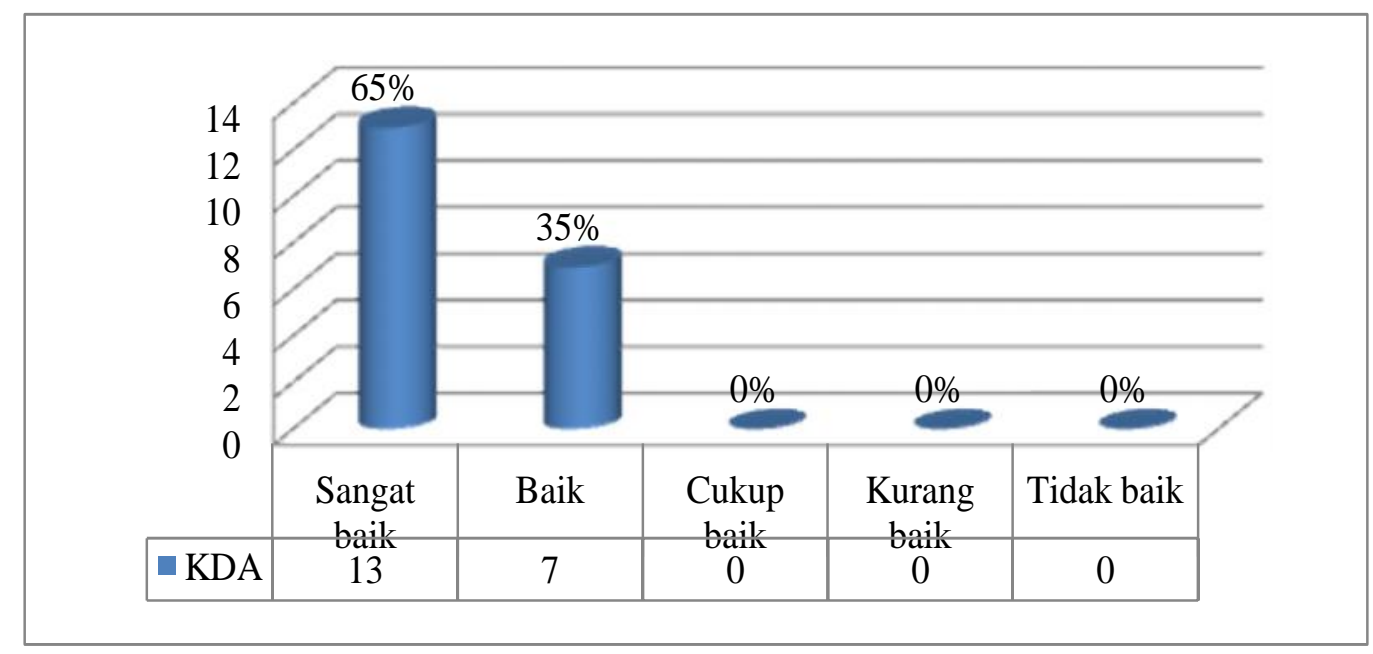

Gambar 1. Interpretasi Konsep Diri Akademik Responden

Konsep diri akademik merupakan kontruksi psikologis yang digunakan untuk menggambarkan keyakinan mahasiswa tentang kemampuan mereka di bidang akademik (Flowers, Raynor, \& White, 2013:1). Persepsi dan usaha akademik ini sangatlah penting sebab sebagai prediktor penting untuk meningkatkan performa dan prestasi akademik. Pada saat yang sama (performa dan prestasi meningkat), individu mulai melakukan evaluasi diri dan menginterpretasi kemampuan akademik yang dimilikinya. Proses ini bersifat kausalistik, sehingga untuk membangun performa dan prestasi akademik mahasiswa, dosen harus memberi perhatian juga kepada konsep diri akademik para mahasiswanya. 
Penelitian ini telah memberi bukti dasar bahwa konsep diri akademik berjalan searah dengan tingkat pendidikan mahasiswa. Semakin tinggi tingkat pendidikan yang ditempuh mahasiswa, semakin tinggi pula konsep diri akademiknya. Tingginya tingkat pendidikan menawarkan determinasi lingkungan belajar yang melibatkan berbagai ras dan golongan serta "ketidaknyamanan" dalam belajar membuat peserta dengan mudah membuat preferensi usaha akademik dan sosial dalam aktivitas pembelajarannya (Bellmore \& Cillessen, 2006:209; Liu \& Wang, 2005:21).

Meski telah menunjukkan konsep diri akademik yang sangat tinggi, mahasiswa tetap saja memiliki kelemahan-kelemahan atau kekurangan-kekurangan ketika mengkontruksi konsep diri akademiknya. Sebagai contoh, berfantasi di dalam kelas dan ketidakkeseriusan dalam mengerjakan tugas belajar. Kasus ini kerap muncul saat mahasiswa tidak memiliki "mood" dalam proses pembelajaran. Untuk itu, dosen perlu melatih mahasiswa mengkonsepsikan diri dalam hal akademik serta desain suasana kelas yang friendly untuk kepentingan pembelajaran.

Konsep diri akademik yang telah terbentuk dengan sangat baik ini $(65 \%)$ harus selalu dijaga dengan metode dan lingkungan belajar yang syarat akan "tuntutan" akademik. Ini dapat terpola dalam proses belajar, karena fasilitas belajar yang tinggi berkorelasi positif dengan tingginya konsep diri akademik dan prestasi akademik mahasiswa (Emmanuel, Adom, Josephine, \& Solomon, 2014:24; Chen, Yeh, Hwang, \& Lin, 2013:172; Dramanu \& Balarabe, 2013:95; Ghazvini, 2011:1034; Srivastava \& Joshi, 2011:331). Hasil positif ini wajibnya dipertahankan dan ditingkatkan, dosen harus dapat menciptakan iklim belajar yang akademistik selama berlangsungnya pembelajaran agar tetap menjaga persepsi dan usaha akademik setiap mahasiswanya.

Saat konsep diri akademik mahasiswa menjadi baik akan sangat berguna atau berdampak terhadap pengaturan pendidikan (Green, Nelson, Martin, \& Marsh, 2006:535), motivasi belajar (Srivastava \& Joshi, 2011:331; Green, Nelson, Martin, \& Marsh, 2006:534), lebih efisien dalam mengatasi masalah, tekun, dan lebih mampu mengontrol waktu belajar (Goldberg, 2014:22), meningkatkan kesejahteraan emosional individu (Srivastava \& Joshi, 2011:331), serta mahasiswa lebih sukses dalam kegiatan pembelajaran (Jen \& Chien, 2008:1).

\section{SIMPULAN DAN SARAN Simpulan}

Hasil penelitian dan diskusi telah membuktikan bahwa mahasiswa semester I program studi S2 pendidikan bahasa dan sastra Inggris Program Pascasarjana Universitas Negeri Surabaya memiliki konsep diri akademik yang sangat baik (65\%). Selain itu, dari dua dimensi konsep diri akademik, mahasiswa memiliki usaha akademik yang lebih baik daripada keyakinan akademiknya (43.75 > 38).

Agar tetap menjaga tren positif konsep diri akademik, mahasiswa harus terbiasa dengan suasana dan iklim belajar yang akademistik. Mahasiswa perlu dibiasakan untuk mempersepsikan diri sebagai pribadi yang memiliki keunggulan atau kelebihan akademik sehingga mampu menyelesaikan tugas dan tanggung jawab belajarnya. Serta dorongan niat untuk tampil maksimal selama proses pembelajaran akan memberikan keseimbangan terhadap niat dan usaha mahasiswa terhadap kualitas akademiknya.

Sebagai mahasiswa kelas tinggi (pascasarjana), dosen dapat menerapkan metode mengajar yang menuntut keterampilan berpikir serta intensitas tugas tingkat tinggi. Ini sebagai upaya dosen untuk membiasakan mahasiswa membentuk komitmennya dalam berkerja dan berupaya melewati setiap "tantangan" dengan strategi yang akseptabel. Dan harapan dan tujuan lebih tinggi adalah model (kerja keras dan usaha) ini dapat didifusikan dalam segala aktivitas akademik mahasiswa yang kompleks (akademik dan non-akademik).

\section{Saran}

Meski menunjukkan konsep diri akademik sangat baik, masih ada mahasiswa yang mengalami kecemasan saat mendapat pertanyaan. Ketidaksiapan ini membuat mahasiswa menghindari pertanyaan-pertanyaan dari dosen atau rekan lainnya saat presentasi. Selain itu, mahasiswa juga menyangsikan kemampuannya untuk sukses disetiap pelajaran dan ini sebagai manifestasi instabilitas kepercayaan akademik.

Ketika tidak fokus, ada responden berfantasi dalam kelas belajar. Ini berlanjut saat mengerjakan tugas-tugas akademiknya. Tugas dikerjakan tanpa mempertimbangan kualitasnya, orientasi pada ketuntasan hanyalah ritual. Alhasil responden ingin kelas belajar segera berlalu. 
Perasaan-perasaan ini bersifat fluktuatif dari usaha akademik responden selama proses pembelajaran dan hanya kasuistik.

\section{DAFTAR PUSTAKA}

Baran, M., \& Maskan, A. K. (2011). A study of relationship between academic self concepts, some selected variables and physics course achievement. International Journal of Education, 3(1), $1-12$.

Bellmore, A. D., \& Cillessen, A. H. N. (2006). Reciprocal influences of victimization, perceived social preference, and self-concept in adolescence. Self and Identity, 5, 209-229.

Chen, S. K., Yeh, Y. C., Hwang, F. M., \& Lin, S. S. J. (2013). The relationship between academic self-concept and achievement: A multicohort-multioccasion study. Learning and Individual Differences, 23, 172-178.

Dramanu, B. Y., \& Balarabe, M. (2013). Relationship between academic self-concept and academic performance of junior high school students in Ghana. European Scientific Journal, 9(34), 93104.

Ellingsen, V. J. (2013). Academic self-concept under typical and maximal environmental press. A research paper submitted in partial fulfilment of the requirements for the masters of science in psychology degree. Georgia Institute of Technology, North Ave NW, Atlanta, United States.

Emmanuel, A. O., Adom, E. A., Josephine, B., \& Solomon, F. K. (2014). Achievement motivation, academic self-concept and academic achievement among high school students. European Journal of Research and Reflection in Educational Science, 2(2), 24-37.

Flowers, L. O., Raynor, J. E., \& White, E. N. (2013). Investigation of academic self-concept of undergraduate in STEM course. Journal of Studies in Social Science, 5(1), 1-11.

Ghazvini, S. D. (2011). Relationships between academic self-concept and academic performance in high school students. Procedia Social and Behavioral Science, 15, 1034-1039.

Goldberg, Y. T. (2014). The effect of ability grouping for talmud on the academic self-concept of jewish orthodox middle school students. A research paper submitted in partial fulfilment of the requirements for the doctor of philosophy in psychology degree. Walden University, Minneapolis, United States.

Green, J., Nelson, G., Martin, A.J., \& Marsh, H. (2006). The causal ordering of self-concept and academic motivation and its effect on academic achievement. International Education Journal, 7(4), 534-546.

Jen, T. H., \& Chien, C. L. (2008). The influences of the academic self-concept on academic achievement: From a perspective of learning motivation (draft). The Proceedings of IRC, 1-8.

Liu, W. C., \& Wang, C. K. J. (2005). Academic self-concept: A cross-sectional study of grade and gender differences in a Singapore secondary school. Asia Pacific Education Review, 6(1), 2027.

Ordaz-Villegas, G., Acle-Tomasini, G., \& Reyes-Lagunes, L. I. (2013). Development of an academic self concept for adolescents (ASCA) scale. Journal of Behavior, Health \& Social Issues, 5(2), 117-130.

Srivastava, R., \& Joshi, S. (2011). The effect of school and area on academic selfconcept and academic achievement of adolescents. Delhi Psychiatry Journal, 14(2), 331-336.

Sternke, J. C. (2010). Self-concept and self-esteem in adolescents with learning disabilities. A research paper submitted in partial fulfilment of the requirements for the masters of science in education degree. University of Wisconsin-Stout, Menomonie, United States.

Tan, J. B. Y., \& Yates, S. M. (2007). A rasch analysis of the academic self-concept questionnaire. International Education Journal, 8(2), 470-484. 
Taylor, L. D., Davis-Kean, P., \& Malanchuk, O. (2007). Self-esteem, academic self-concept, and aggression at school. Aggressive Behavior, 33, 130-136.

Yengimolki, S., Kalantarkousheh, S. Y., \& Malekitabar, A. (2015). Self-concept, social adjustment and academic achievement of Persian student. International Review of Social Science and Humanities, 8(2), 50-60.

Profile Singkat

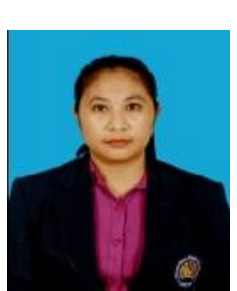

Zuvyti A. Tlonaen, lahir di Kupang, 17 Januari 1985; menyelesikan pendidikan sarjana pada program studi bahasa dan sastra Inggri, Universitas Warmadewa, Bali (2003-2007). Melanjutkan pendidikan magister pada program studi pendidikan bahasa dan sastra Inggris, Universitas Negeri Surabaya (2016 sampai sekarang). Sebagai dosen tetap program studi Pendidikan Bahasa Inggris, Fakultas Keguruan dan Ilmu Pendidikan, Universitas Kristen Artha Wacana, Kupang

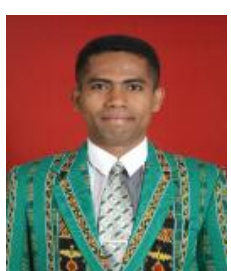

Jusuf Blegur, lahir di Kalabahi, 04 Juli 1988; menyelesikan pendidikan sarjana pada program studi pendidikan jasmani, kesehatan, dan rekreasi, Universitas Kristen Artha Wacana, Kupang (2006-2011) dan magister pada program studi pendidikan olahraga, Universitas Negeri Surabaya (20112013). Sejak bulan April 2014 tercatat sebagai dosen tetap program studi Pendidikan Jasmani, Kesehatan, dan Rekreasi, Fakultas Keguruan dan Ilmu Pendidikan, Universitas Kristen Artha Wacana, Kupang 